\title{
Red luminescence from hydrothermally synthesized Eu-doped ZnO nanoparticles under visible excitation
}

\author{
$P$ M ANEESH and M K JAYARAJ* \\ Department of Physics, Cochin University of Science and Technology, Kochi 682 022, India
}

MS received 16 May 2008; revised 9 February 2010

\begin{abstract}
Eu-doped ZnO nanoparticles were synthesized by hydrothermal method. The Eu-dopant concentration has been varied by varying the amount of Eu-dopant concentration. These nanoparticles were structurally characterized by X-ray diffraction, transmission electron microscopy and selected area electron diffraction and it confirms the formation of nanoparticles having standard wurtzite structure. Photoluminescence studies show that these nanoparticles exhibit a sharp red luminescence due to the intra- $4 \boldsymbol{f}$ transitions of $\mathrm{Eu}^{3+}$ ions at an excitation of $397 \mathrm{~nm}$ and $466 \mathrm{~nm}$. Luminescence quenching is observed in the nanoparticles as the Eu-dopant concentration increases. Incorporation of $\mathrm{Eu}$ in the nanoparticles was confirmed by the energy dispersive $\mathrm{X}$-ray studies.
\end{abstract}

Keywords. Zinc oxide; X-ray diffraction; transmission electron microscopy; photoluminescence; luminescence quenching.

\section{Introduction}

Phosphor, which has high efficiency and low degradation, is required for the development of lighting technology and for flat panel displays such as field emission displays (FEDs) and plasma display panels (PDPs) (Blasse and Grabmaier 1994; Yen and Shionoya 1998). The use of oxide phosphors in place of conventional sulphide phosphors has been preferred for FED applications due to higher stability in high vacuum environment and less emission of contaminating gases (Itoh et al 1991).

High quality II-VI semiconductor nanocrystals and their luminescence properties have been studied recently both experimentally and theoretically (Murray et al 1993; Nirmal et al 1996; Empedocles et al 1996; Efros and Rosen 1997; Matsuura et al 2000). The II-VI semiconductor nanomaterials are unique host materials for doping of highly optically active impurities, and semiconductor doped with luminescence centres exhibit efficient luminescence even at room temperature (Bhargava et al 1994; Bol and Meijerink 1998).

In recent years, rare earth (RE) doped wide bandgap semicoducting nanomaterials have attracted wide use in various applications such as thin film electroluminescent (TFEL) devices (Kossanyi et al 1990), optoelectronic or cathodoluminescent devices (Leskela 1998). RE-doped insulators are used in telecommunications, lasers and amplifiers (Jacquier et al 2000), medical analysis and phosphors (Blasse and Grabmaier 1994), etc.

\footnotetext{
*Author for correspondence (mkj@cusat.ac.in)
}

CdSe and CdS are the most widely studied among the II-VI semiconductor nanoparticles (Murray et al 1993; Brus et al 1996; Nirmal et al 1996; Empedocles et al 1996; Matsuura et al 2000; Peng et al 2000; Hu et al 2001). However, these materials contain toxic elements such as $\mathrm{Cd}$ and Se. Zinc oxide $(\mathrm{ZnO})$ is a wide bandgap $(3.3 \mathrm{eV})$ II-VI compound semiconductor with large exciton binding energy $(60 \mathrm{meV})$ at room temperature. $\mathrm{ZnO}$ is an environmentally friendly material and is one of the suitable candidates for practical use as a nanodevice material. It has a stable wurtzite structure with lattice spacing, $a=0.325 \mathrm{~nm}$ and $c=0.521 \mathrm{~nm}$. Most of the $\mathrm{ZnO}: \mathrm{RE}^{3+}$ crystals have been synthesized by traditional high temperature solid state method (Kossanyi et al 1990; Kouyate et al 1991; Bachir et al 1996, 1997) which is energy consuming and difficult to control the particle properties.

Rare-earth (RE) ions are better luminescent centres than the transition metal elements because their $4 f$ intrashell transitions originate at narrow and intense emission lines. In this paper, we report the synthesis of Eu-doped $\mathrm{ZnO}$ nanoparticles by low temperature hydrothermal method and their photoluminescence emission characteristics.

\section{Experimental}

The Eu-doped $\mathrm{ZnO}$ nanoparticles were synthesized from the stock solutions of $\mathrm{Zn}\left(\mathrm{CH}_{3} \mathrm{COO}\right)_{2} \cdot 2 \mathrm{H}_{2} \mathrm{O}(0 \cdot 1 \mathrm{M})$ prepared in $50 \mathrm{ml}$ methanol under stirring. To this solution, $\mathrm{Eu}_{2} \mathrm{O}_{3}$ varying from $0.005-0.03 \mathrm{~g}$ was added. This led to europium concentration variation from $1.2-5.27$ at. $\%$ in 
the $\mathrm{ZnO}$ nanoparticle. $25 \mathrm{ml}$ of $\mathrm{NaOH}(0 \cdot 3 \mathrm{M})$ solution prepared in methanol was mixed with the above solution under continuous stirring in order to get the $\mathrm{pH}$ of reactants between 8 and 11. These solutions were transferred into teflon lined sealed stainless steel autoclaves and maintained at $150^{\circ} \mathrm{C}$ for $12 \mathrm{~h}$ under autogenous pressure. It was then allowed to cool naturally to room temperature. After the reaction was complete, the resulting white solid products were washed with methanol, filtered and then dried in air in a laboratory oven at $60^{\circ} \mathrm{C}$. The undoped $\mathrm{ZnO}$ nanoparticles were also synthesized in a similar manner described above but without adding $\mathrm{Eu}_{2} \mathrm{O}_{3}$.

The synthesized samples were characterized for their structure by X-ray diffraction (Rigaku D max-C) with $\mathrm{CuK} \alpha$ radiation. Transmission electron microscopy (TEM), selected area electron diffraction (SAED) and high resolution transmission electron microscopy (HRTEM) were performed with a JEOL JEM-3100F transmission electron microscope operating at $200 \mathrm{kV}$. The sample for TEM was prepared by placing a drop of the $\mathrm{ZnO}$ suspension in methanol onto a standard carbon coated copper grid. The grids were dried before recording the micrographs. The elemental composition of the Eu-doped $\mathrm{ZnO}$ nanoparticles were determined using energy dispersive X-ray spectroscopy (EDX). Room temperature photoluminescence (PL) of the samples was measured on Horiba Jobin Yvon Fluoromax-3 spectrofluorimeter using Xe lamp as the excitation source.

\section{Results and discussion}

The X-ray diffraction data were recorded with $\mathrm{CuK} \alpha$ radiation $(1.5418 \AA)$. The intensity data were collected over a $2 \theta$ range of $20-80^{\circ}$.

All the peaks in the X-ray diffraction pattern (figure 1) are assigned to the typical wurtzite structure of $\mathrm{ZnO}$ (ICSD Card No. 086254). There are no characteristic peaks of $\mathrm{Eu}_{2} \mathrm{O}_{3}$ regardless of the Eu-dopant concentration. Thus the wurtzite structure is not modified by the addition of $\mathrm{Eu}$ into the $\mathrm{ZnO}$ matrix. The average grain size $(D)$ of the samples was estimated with the help of Scherrer equation using the diffraction intensity of (101) peak (Klug and Alexander 1954):

$$
D=0 \cdot 89 \lambda /(\beta \cos \theta)
$$

where $\lambda$ is the $\mathrm{X}$-ray wavelength, $\beta$ the full width at halfmaximum (FWHM) of the $\mathrm{ZnO}$ (101) line and $\theta$ the diffraction angle.

The broadening of the diffraction peaks is an indication that the synthesized materials are in nanometer regime. The grain size was found to be in the range of 9-12 nm depending on the growth condition. The lattice parameters calculated were also in agreement with the reported values.
EDX results show that the elemental percentage of the $\mathrm{Eu}$ ions incorporated in the Eu-doped $\mathrm{ZnO}$ nanoparticles are $1.2,2 \cdot 3,4.53$ and 5.27 at.\% as 0.005, 0.01, 0.02 and $0.03 \mathrm{~g} \mathrm{Eu}_{2} \mathrm{O}_{3}$ were used in the precursor solution.

Figure 2(a) shows TEM image and the corresponding SAED pattern of 2.3 at.\% Eu-doped $\mathrm{ZnO}$ synthesized by hydrothermal method. TEM image confirms the formation of nanoparticles and it has an average size of $8 \mathrm{~nm}$ and they are spherical in shape. This result is consistent with what we had obtained from XRD analysis. From the diffraction rings in the SAED pattern, (002), (102) and (110) planes of $\mathrm{ZnO}$ were identified.

Figure 2(b) shows TEM image and the corresponding SAED pattern of 3.78 at.\% Eu-doped $\mathrm{ZnO}$ by hydrothermal method. TEM image confirms the size of the particles to be in the nanoregime. These are not spherical in shape and it has a length of $20 \mathrm{~nm}$ and diameter of $7 \mathrm{~nm}$. From the diffraction rings in the SAED pattern, (002), (102) and (110) planes of $\mathrm{ZnO}$ were identified.

Figure 3(a) shows the photoluminescent emission spectra of Eu-doped $\mathrm{ZnO}$ nanoparticles at an excitation wavelength $\left(\lambda_{\text {exc }}\right)$ of $397 \mathrm{~nm}$. The excitation energy almost coincides with the energy of ${ }^{7} F_{0} \rightarrow{ }^{5} L_{6}$ transitions of $\mathrm{Eu}^{3+}$ ions, which is $3.147 \mathrm{eV}$ (Peres et al 2007). Excitation at $397 \mathrm{~nm}$ yields the characteristic emissions of $\mathrm{Eu}^{3+}$ corresponding to ${ }^{5} D_{j}(j=0,1) \rightarrow{ }^{7} F_{j}(j=0,1,2,3$ and 4$)$. The direct excitation of $\mathrm{Eu}^{3+}$ enhances the PL due to $\mathrm{Eu}^{3+}$ ions. The emission at $596 \mathrm{~nm}$ originates from the magneticdipole allowed ${ }^{5} D_{0} \rightarrow{ }^{7} F_{1}$ transition, indicating that $\mathrm{Eu}^{3+}$ ions occupy a site with inversion symmetry and $617 \mathrm{~nm}$ from electric-dipole allowed ${ }^{5} D_{0} \rightarrow{ }^{7} F_{2}$ transition, which results in a large transition probability in the crystal field with inversion antisymmetry. The intensity of emission corresponds to the ${ }^{5} D_{0} \rightarrow{ }^{7} F_{2}$ transition which is stronger than that of ${ }^{5} D_{0} \rightarrow{ }^{7} F_{1}$ transition. It is suggested that the

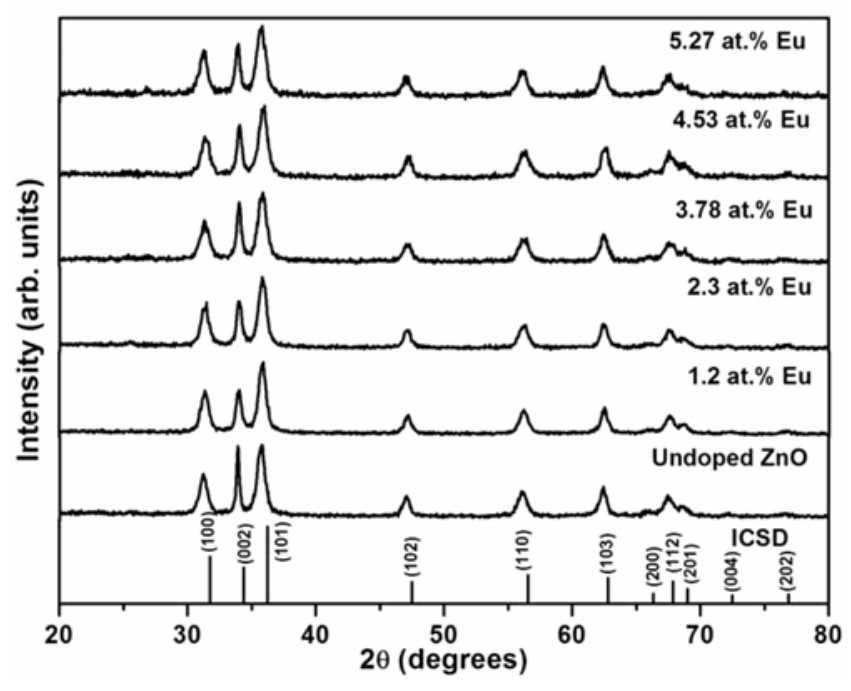

Figure 1. XRD pattern of undoped $\mathrm{ZnO}$ and Eu-doped $\mathrm{ZnO}$ nanoparticles of varying Eu dopant concentration. 

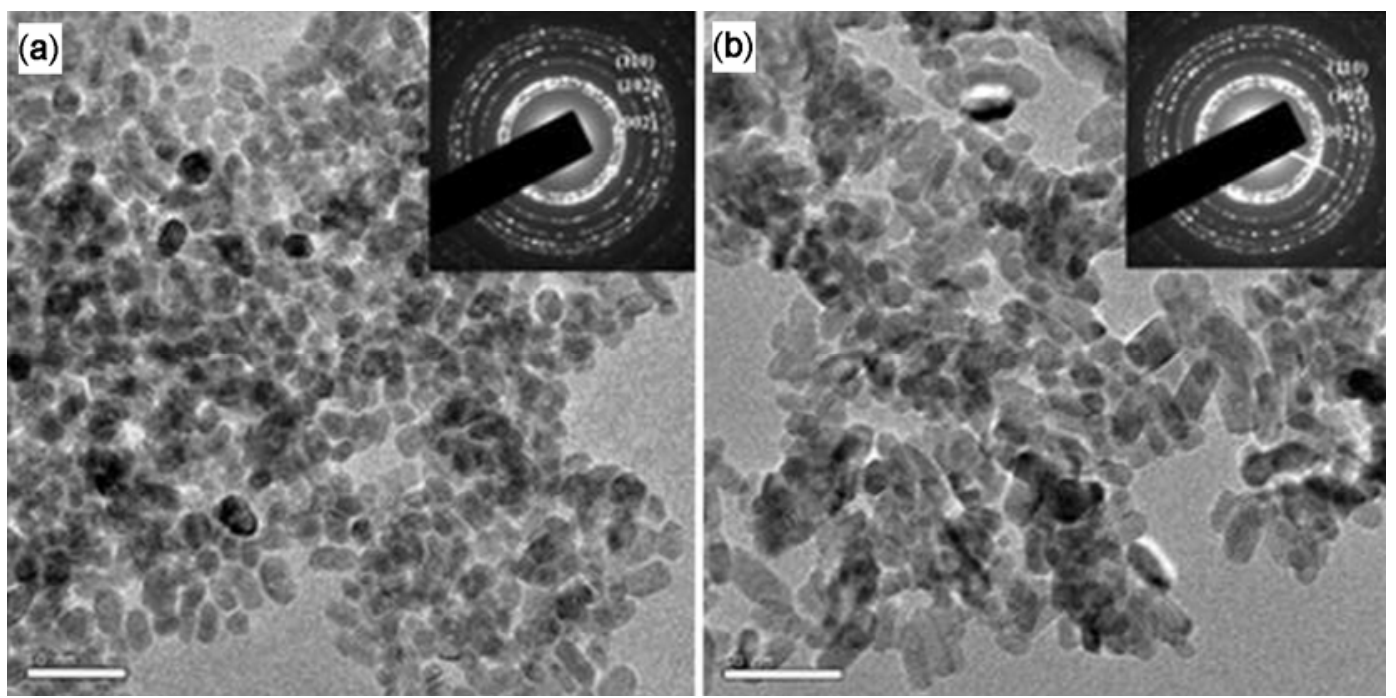

Figure 2. TEM image of Eu-doped $\mathrm{ZnO}$ nanoparticles with (a) 1.2 at.\% and (b) 3.78 at.\% Eu dopant concentration. SAED pattern of the $\mathrm{ZnO}$ : Eu with (a) 1.2 at.\% and (b) 3.78 at.\% Eu dopant concentration is in the inset.
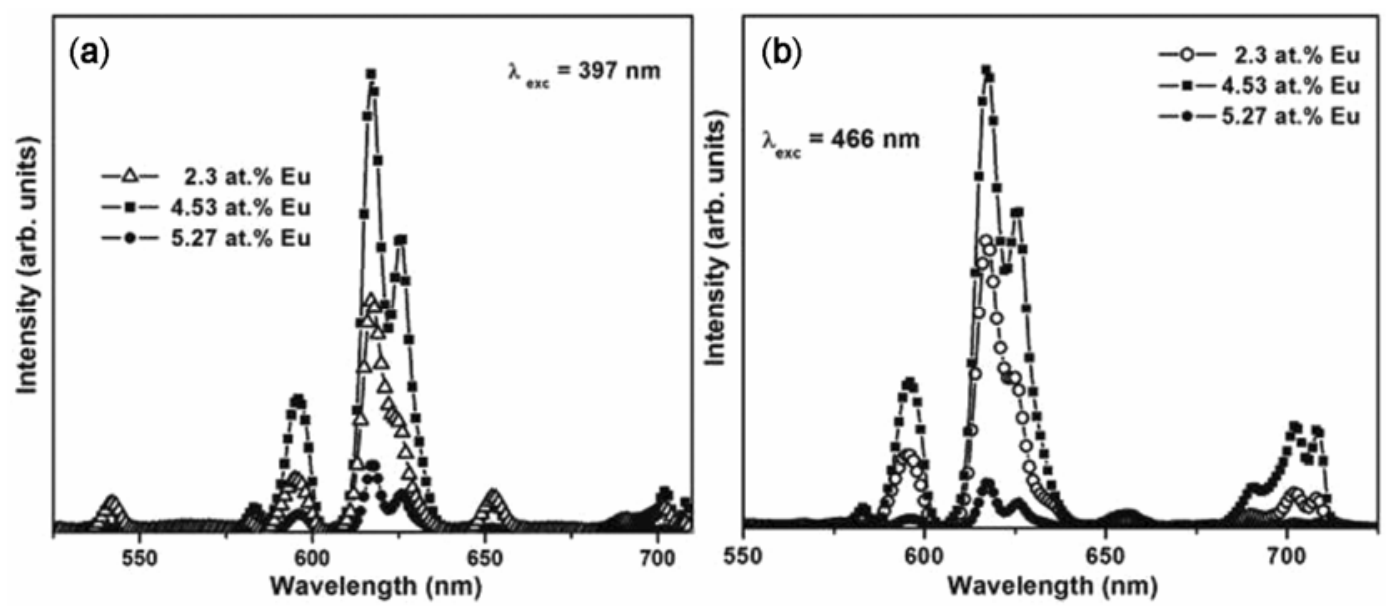

Figure 3. Room temperature photoluminescence emission spectra of Eu-doped $\mathrm{ZnO}$ nanoparticles excited for various Eu dopant concentrations at an excitation wavelength of (a) $397 \mathrm{~nm}$ and (b) $466 \mathrm{~nm}$.

$\mathrm{Eu}^{3+}$ ions mainly take a site with inversion antisymmetry in the $\mathrm{ZnO}$ host. The emission at $701 \mathrm{~nm}$ is from ${ }^{5} D_{0} \rightarrow{ }^{7} F_{4}$ transition and at $653 \mathrm{~nm}$ is from ${ }^{5} D_{0} \rightarrow{ }^{7} F_{3}$ transition. The emission peaks at $583 \mathrm{~nm}$ corresponds to ${ }^{5} D_{0} \rightarrow{ }^{7} F_{0}$ transition. The observation of forbidden ${ }^{5} D_{0} \rightarrow{ }^{7} F_{0}$ transition indicates that some of the Eu ions are at low site symmetry. The emission at $543 \mathrm{~nm}$ is from ${ }^{5} D_{1} \rightarrow{ }^{7} F_{1}$ transition.

The luminescent intensity of Eu-doped $\mathrm{ZnO}$ nanoparticles increases with increase in the Eu-dopant concentration at first and then it decreases. When the activator concentration increases above a certain level, luminescence begins to quench. Thus the emission intensity of ${ }^{5} D_{0} \rightarrow{ }^{7} F_{j}(j=0-4)$ depends on Eu-dopant concentration. In this case, the pairing or aggregation of activator atoms at high concentration may change a fraction of the acti- vators into quenchers and induce the quenching effect. The migration of excitation by resonant energy transfer between the $\mathrm{Eu}^{3+}$ activators can sometimes be so efficient that it may carry the energy to a distant killer or to a quenching centre existing at the surface of the crystal.

Figure 3(b) shows the photoluminescent emission spectra of Eu-doped $\mathrm{ZnO}$ nanoparticles excited at $466 \mathrm{~nm}$. The peaks at 583,596,617, 653 and $701 \mathrm{~nm}$ corresponding to the ${ }^{5} D_{0} \rightarrow{ }^{7} F_{j}(j=0-4)$ transitions of $\mathrm{Eu}^{3+}$ ions are dominated by the ${ }^{5} D_{0} \rightarrow{ }^{7} F_{2}$ transition at $617 \mathrm{~nm}$. In addition, the emission intensity increases with increasing Eu dopant concentration up to 4.53 at.\% and then it decreases due to the concentration quenching.

Figure 4 shows the room temperature photoluminescence emission spectrum of the $\mathrm{ZnO}$ nanoparticles excited at $362 \mathrm{~nm}$. Green emission at $545 \mathrm{~nm}$ was observed from 
the hydrothermally synthesized $\mathrm{ZnO}$ nanoparticles. It can be attributed to the transition between singly charged oxygen vacancy and photo excited hole or $\mathrm{Zn}$ interstitial related defects (Vanheusden et al 1996; Peng et al 2006; Aneesh et al 2007). The inset in figure 4 shows the photoluminescent excitation spectra of the $\mathrm{ZnO}$ nanoparticles $\left(\lambda_{\mathrm{em}}=545 \mathrm{~nm}\right)$ which indicates that the excitation is at $362 \mathrm{~nm}$. The excitation peak corresponds to the band to band transition which shows a blue shift in the bandgap of $\mathrm{ZnO}$ nanoparticles.

Figure 5 shows the variation of PL integral intensity, at an excitation wavelength of $397 \mathrm{~nm}$ and $466 \mathrm{~nm}$, as

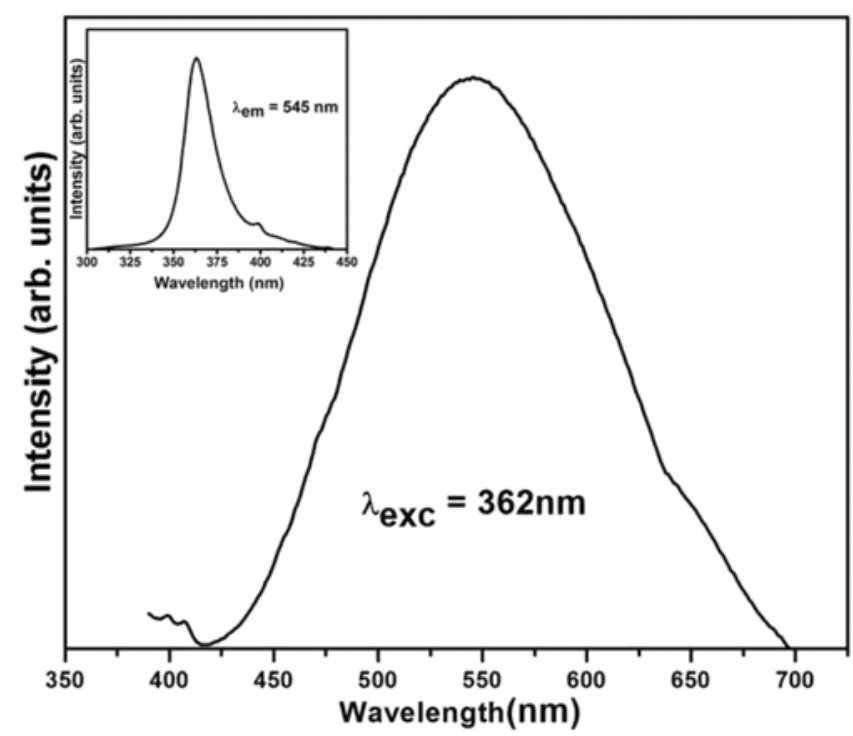

Figure 4. Room temperature photoluminescence spectra of $\mathrm{ZnO}$ nanoparticle excited at $\lambda_{\mathrm{exc}}=362 \mathrm{~nm}$. The inset shows the corresponding photoluminescent excitation spectra $\left(\lambda_{\mathrm{em}}=\right.$ $545 \mathrm{~nm}$ ) of ZnO nanoparticles.

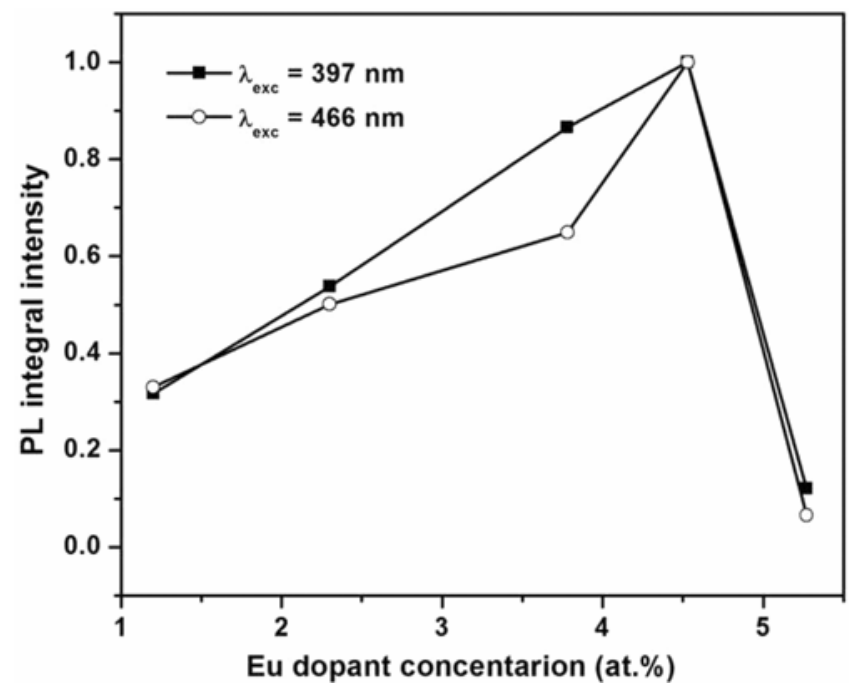

Figure 5. Variation of PL integral intensity with amount of Eu dopant concentration under $397 \mathrm{~nm}$ and $466 \mathrm{~nm}$ excitations. the $\mathrm{Eu}$ dopant concentration in $\mathrm{ZnO}$ increases from $1 \cdot 2$ 5.27 at.\%. The PL integral intensity increases with increasing amount of $\mathrm{Eu}$ dopant concentration up to 4.53 at. $\%$ and then it decreases due to the concentration quenching.

When the nanoparticles are excited with a wavelength of $325 \mathrm{~nm}$, no intra- $4 f^{6} \mathrm{Eu}^{3+}$ related emission is observed. The disappearance of the red emission excited at $325 \mathrm{~nm}$ wavelength is probably related to the shielding effect due to the existence of the $\mathrm{Eu}_{\mathrm{Zn}}$ * level (Yang et al 2006).

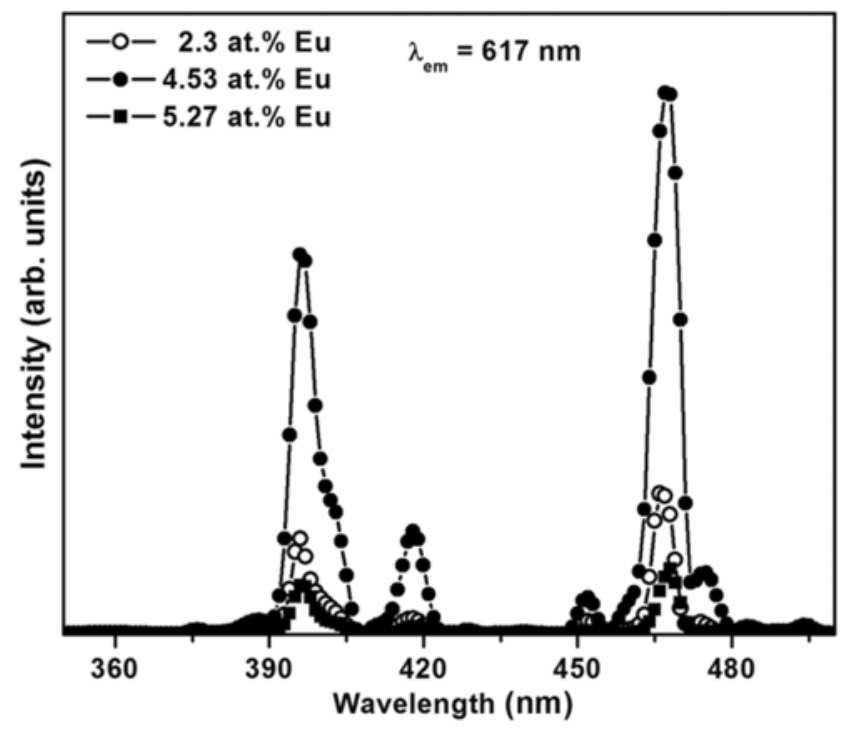

Figure 6. Room temperature photoluminescent excitation spectra of Eu-doped $\mathrm{ZnO}$ nanoparticles $\left(\lambda_{\mathrm{em}}=617 \mathrm{~nm}\right)$.

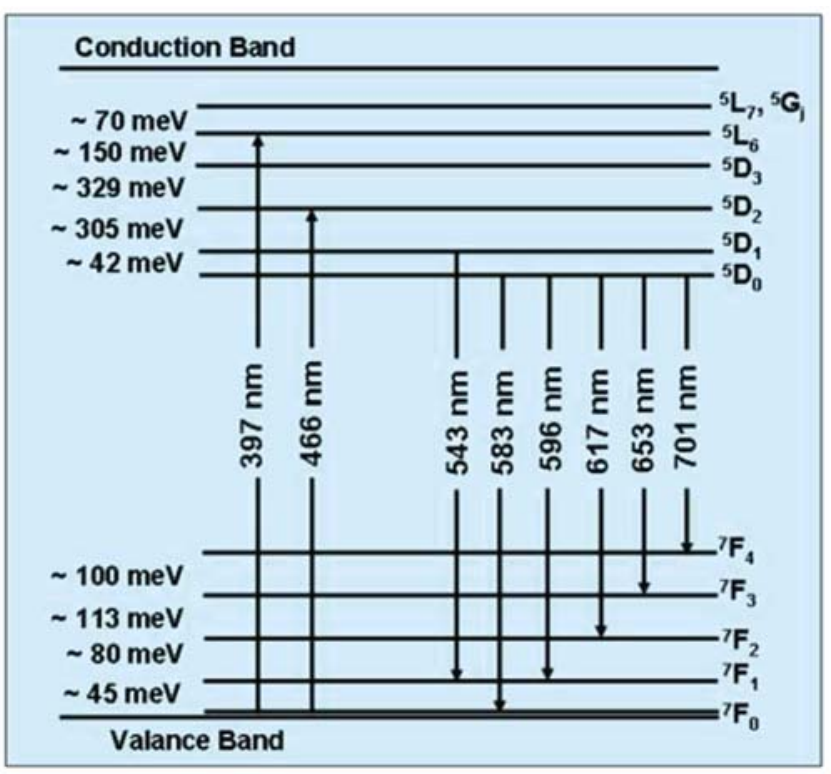

Figure 7. Simplified energy diagram of $\mathrm{Eu}^{3+}$ in Eu-doped $\mathrm{ZnO}$ nanoparticles. The energies of absorption and emission lines are also shown. 


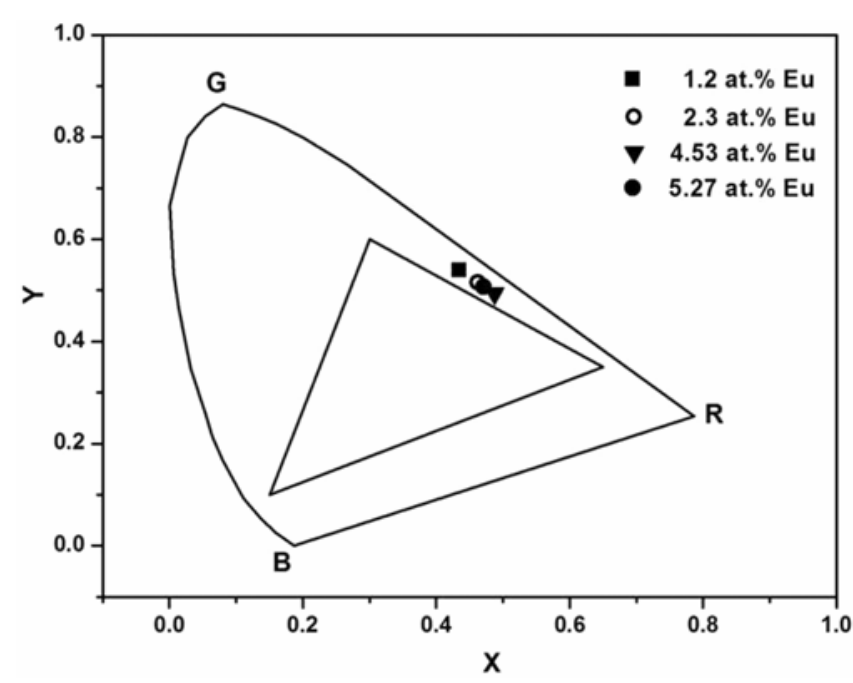

Figure 8. CIE diagram of Eu-doped $\mathrm{ZnO}$ nanoparticles synthesized by varying the Eu dopant concentration (1.2$5 \cdot 27$ at.\%).

Thus $325 \mathrm{~nm}$ photon is not in resonance with any transitions of $\mathrm{Eu}^{3+}$ ions.

Figure 6 shows the photoluminescent excitation (PLE) spectra of the Eu-doped $\mathrm{ZnO}$ nanoparticles $\left(\lambda_{\mathrm{em}}=\right.$ $617 \mathrm{~nm}$ ) which indicates that the excitation is at 397 and $466 \mathrm{~nm}$. The excitation peaks at $397 \mathrm{~nm}$ and $466 \mathrm{~nm}$ corresponds to the ${ }^{7} F_{0} \rightarrow{ }^{5} L_{6}$ and ${ }^{7} F_{0} \rightarrow{ }^{5} D_{2}$ transitions of $\mathrm{Eu}^{3+}$ ions. The peak at $418 \mathrm{~nm}$ corresponds to the $4 F \rightarrow 5 D$ transition of $\mathrm{Eu}^{2+}$ ion (Zhang et al 2007). It also shows that the PLE intensity increases with increase in the Eu dopant concentration up to 4.53 at. $\%$ and then it decreases. Figure 7 shows a schematic representation of the main energy levels identified in the studied samples (Peres et al 2007).

The CIE colour coordinates measured from the photoluminescent emission of Eu-doped $\mathrm{ZnO}$ nanoparticles by varying the Eu dopant concentration are shown in figure 8. For the case of the Eu-doped $\mathrm{ZnO}$ nanoparticles with $\mathrm{Eu}$ dopant concentration of 1.2 at.\%, 2.3 at.\%, 4.53 at. $\%$ and 5.27 at. $\%$, the CIE coordinates are $(0.43,0.54),(0.46$, $0.52),(0.49,0.49)$ and $(0.47,0.51)$, respectively and these show the colors in yellowish-orange and yellow regions.

\section{Conclusions}

Europium doped $\mathrm{ZnO}$ nanoparticles were synthesized by hydrothermal method by varying the Eu dopant concentration. XRD and SAED results show these nanoparticles have wurtzite structure and the particle size distributions were studied from the TEM. The red PL emissions from the intra- $4 f$ transition of $\mathrm{Eu}^{3+}$ ions are observed under an excitation of 397 and $466 \mathrm{~nm}$. Luminescence quenching is observed in the nanoparticles as the Eu-dopant concentration increases. Incorporation of $\mathrm{Eu}$ in the nanoparticles was confirmed by EDX studies.

\section{Acknowledgements}

The work is supported by the Department of Science and Technology, Government of India, under nanoscience and technology initiative. The authors thank the Sophisticated Analysis Instrument Facility Centre, IIT Chennai, for TEM measurements. One of the authors (PMA) thanks the Kerala State Council for Science, Technology and Environment for the award of a research fellowship.

\section{References}

Aneesh P M, Vanaja K A and Jayaraj M K 2007 Proc. SPIE 6639 6690J

Bachir S, Azuma K, Kossanyi J, Valat P and Ronfard-Haret J C 1997 J. Luminesc. 7535

Bachir S, Sandouly C, Kossanyi J and Ronfard-Haret J C 1996 J. Phys. Chem. Solids 571869

Bhargava R N, Gallagher D, Hong X and Nurmikko A 1994 Phys. Rev. Lett. 72416

Blasse G and Grabmaier B C 1994 Luminescent materials (New York: Springer)

Bol A A and Meijerink A 1998 Phys. Rev. B58 R15997

Brus L E, Efros Al L and Itoh T 1996 J. Lumin. 701

Efros Al L and Rosen M 1997 Phys. Rev. Lett. 781110

Empedocles S A, Norris D J and Bawendi M G 1996 Phys. Rev. Lett. 773873

Hu J, Li L S, Yang W, Manna L, Wang L W and Alivisatos A P 2001 Science 2922060

Itoh S, Toki H, Sato Y, Morimoto K and Kishino T 1991 J. Electrochem. Soc. 1381509

Jacquier B, Lebrasseur E, Guy S, Belarouci A and Menchini F 2000 J. Alloys Compds. 303207

ICSD Card No. 086254

Klug H P and Alexander LE 1954 X-ray diffraction: Procedures for polycrystalline and amorphous materials (New York: Wiley) 1st edn, Ch. 9

Kossanyi J et al 1990 J. Lumin. 4617

Kouyate D, Ronfard-Haret J C and Kossanyi J 1991 J. Lumin. 50205

Leskela M 1998 J. Alloys Compds. 275702

Matsuura D, Kanemitsu Y, Kushida T, White C W, Budai J D and Meldrum A 2000 Appl. Phys. Lett. 772289

Murray C B, Norris D J and Bawendi M G $1993 \mathrm{~J}$. Am. Chem. Soc. 1158706

Nirmal N, Dabbousi B O, Bawendi M G, Macklin J I, Trautman J K, Harris T D and Brus L E 1996 Nature (London) 383802

Peng X, Manna L, Yang W, Wickham J, Scher E, Kadavanich A and Alivisatos A P 2000 Nature (London) 40459

Peng W Q, Qu S C, Cong G W and Wang Z G 2006 Mater. Sci. Semicond. Process. 9156

Peres M et al 2007 Appl. Phys. A88 129

Vanheusden K, Warren W L, Seager C H, Tallant D R, Voigt J A and Gnade B E 1996 J. Appl. Phys. 797983

Yang C C, Cheng S Y, Lee H Y and Chen S Y 2006 Ceram. Int. 3237

Yen W M and Shionoya S (eds) 1998 Phosphor handbook (Boca Raton, FL: CRC Press)

Zhang X, Wang J, Zhang J and Su Q 2007 Mater. Lett. 61761 